\title{
Comprehensive ripeness-index for prediction of ripening level in mangoes by multivariate modelling of ripening behaviour
}

\author{
Vijayaram Eyarkai Nambi ${ }^{1 *}$, Kuladaisamy Thangavel ${ }^{2}$, Annamalai Manickavasagan ${ }^{3}$, and Sultan Shahir ${ }^{4}$ \\ ${ }^{1}$ Central Institute of Post-harvest Engineering and Technology, Ludhiana, India \\ ${ }^{2}$ Horticultural College and Research Institute, Tamil Nadu Agricultural University, Coimbatore, India \\ ${ }^{3}$ Department of Soils, Water and Agricultural Engineering, Sultan Qaboos University, Sultanate of Oman \\ ${ }^{4}$ T.K.M.Institute of Technology, Kollam, India
}

Received June 28, 2016; accepted December 8, 2016

\begin{abstract}
A b s r a c t. Prediction of ripeness level in climacteric fruits is essential for post-harvest handling. An index capable of predicting ripening level with minimum inputs would be highly beneficial to the handlers, processors and researchers in fruit industry. A study was conducted with Indian mango cultivars to develop a ripeness index and associated model. Changes in physicochemical, colour and textural properties were measured throughout the ripening period and the period was classified into five stages (unripe, early ripe, partially ripe, ripe and over ripe). Multivariate regression techniques like partial least square regression, principal component regression and multi linear regression were compared and evaluated for its prediction. Multi linear regression model with 12 parameters was found more suitable in ripening prediction. Scientific variable reduction method was adopted to simplify the developed model. Better prediction was achieved with either 2 or 3 variables (total soluble solids, colour and acidity). Cross validation was done to increase the robustness and it was found that proposed ripening index was more effective in prediction of ripening stages. Three-variable model would be suitable for commercial applications where reasonable accuracies are sufficient. However, 12-variable model can be used to obtain more precise results in research and development applications.

$\mathrm{K}$ e y w o r d s: ripening level, alphonso, banganapalli mango ripening, multi linear regression, partial least square regression, and modelling of ripening
\end{abstract}

\section{INTRODUCTION}

Among climacteric fruits, mango (Mangiferaindica L.) is one of the most important species. India ranks first in mango production in the world, accounting for $41.5 \%$ (FAOSTAT), and the annual production is estimated to be nearly 18 million t (Saxena and Gandhi, 2015). The com-

*Corresponding author e-mail: eyarkainambi@gmail.com mercial pack houses and pulping industries need a rapid quality inspection method for the prediction of fruit ripeness level or stage.

Fruit ripening is a highly coordinated, genetically programmed, and irreversible phenomenon involving a series of physiological, biochemical, and organoleptic changes that lead to the development of a soft and edible ripe fruit with desirable quality attributes (Prasanna et al., 2007). The degree of ripeness or level of ripening of climacteric fruits is an important criterion for determining the optimal post-harvest strategies for handling and marketing of the fruits. Changes in biochemical, physiological composition, colour, textural and rheological properties associated with ripening have been reviewed and reported by many researchers (Bashir and Abu-Goukh, 2003; Brady, 1987; Charles and Tung, 1973; Chen and Ramaswamy, 2002; Lizada, 1993; Nambi et al., 2016a, 2016b; Seymour et al., 1993; Stover and Simmonds, 1987).

Padda et al. (2011) compared firmness, total soluble solids (TSS) and dry matter to assess the ripening in mangoes using principal component analysis (PCA) and reported that firmness test with penetrometer was suitable to assess changes. Kienzle et al. (2012) studied the effect of harvest time on post-harvest quality using multivariate methods. But these studies did not propose any consolidated model or index to quantify or predict ripeness level. Saranwong et al. (2004) and Rungpichayapichet et al. (2016) reported on the prediction of ripeness and eating quality of mangoes using NIR spectroscopy. All these methods cannot be used

(C) 2017 Institute of Agrophysics, Polish Academy of Sciences 
as a ready reckoner with minimum inputs, and they need high cost instruments like NIR spectrometer and complex algorithms.

Vásquez-Caicedo et al. (2005) proposed a ripening index (RPI) for mango ripeness, combining the fruit firmness with sugar acid ratio. A vast range of RPI values were reported in many studies (Blanes et al., 2015; Kienzle et al., 2012; Rungpichayapichet et al., 2016). Even negative RPI values were found for ripe fruits in our preliminary study (Nambi et al., 2015). So RPI may not be correlated directly with ripening stages, since the vast range of RPI values, including negative numbers, leads to confusion, moreover demarcation of RPI could not be done for different ripening levels.

Ripening class index (Rci) was proposed by Joas et al. (2009) based on respiration rate. The Rci does not account for changes of internal and external quality parameters. Jha et al. (2007) reported a model for predicting harvest maturity using colour coordinates with the help of maturity index $\left(I_{m}=T S S / 8\right.$ 100) which was developed to assess the appropriate harvest time. The proposed models would not be suitable for ripening, since the model did not deal with the changes during ripening.

Modelling of ripening behaviour would fulfil the need for rapid prediction of ripening level of fruits. Mathematical modelling is gaining interest in predicting chemical, physical and microbiological changes during food processing and storage. It can provide easy prediction and access for further simulation of any process. An index which is capable of explaining the ripening level / behaviour / stage explicitly, with inclusion of all changes occurring in physicochemical, colour and textural properties during fruit ripening, would be more appropriate for ripening prediction. For consolidating the changes in physicochemical, colour and textural properties cumulatively, a higher end statistical approach needs to be adopted while developing such an index. At the same time, the index should be easy to compute and calculate with readily measurable parameters.

Therefore, the objective of this study was to evaluate three multivariate regression techniques (partial least square regression (PLS), principal component regression (PCR) and multi linear regression (MLR)) to predict ripening index $\left(I_{R}\right)$ in three mango varieties using measured quality attributes.

\section{MATERIALS AND METHODS}

Three cultivars of mango (Alphonso, Banganapalli and Neelam) were collected at 100-105DFFB (days from full bloom) maturity from two different locations of Tamil Nadu, India, for two seasons (2014 and 2015). Samples collected in 2014 were used in model calibration and those collected in 2015 were used in model validation. The collected mangoes were prepared and kept for ripening as proposed by Nambi et al. (2015). From the harvested lot, sound man- goes were culled out, desapped, washed and shade-dried for $30 \mathrm{~min}$. The selected mangoes were treated with $200 \mathrm{ppm}$ ethylene $(0.02 \%)$ for $24 \mathrm{~h}$ in a ripening chamber at $20^{\circ} \mathrm{C}$ with $85 \% \mathrm{RH}$. After the treatment, the mangoes were kept for ripening at the same temperature and $\mathrm{RH}\left(20^{\circ} \mathrm{C}\right.$ and $85 \% \mathrm{RH})$. Three random samples from each variety were taken at $24 \mathrm{~h}$ intervals for quality measurement.

The quality parameters, viz. TSS, $\mathrm{pH}$, external and internal colour values, titrable acidity (TA) and textural parameters were measured throughout the ripening period. Homogenised mango pulp was obtained with laboratory mixer to determine TSS and TA as reported by VásquezCaicedo et al. (2005). TSS was measured using a digital refractometer (ATAGO Co Ltd., Japan) in ${ }^{\circ}$ Brix. The $\mathrm{pH}$ value was measured by using a digital $\mathrm{pH}$ meter (Systronics $\mu \mathrm{pH}$ system, India). The TA was calculated as grams citric acid equivalent $/ 100 \mathrm{~g}$ sample.

The textural characteristics were measured using the Texture Analyzer (TA-HDi, Stable Micro Systems, UK). $4 \mathrm{~mm}$ cylindrical probe $(\mathrm{P} / 4)$ was used with $1 \mathrm{~mm} \mathrm{~s}^{-1}$ pre-test speed, $0.1 \mathrm{~mm} \mathrm{~s}^{-1}$ test speed, $1 \mathrm{~mm} \mathrm{~s}^{-1}$ post-test speed, and $10 \mathrm{~mm}$ penetration depth to obtain force displacement curve. Peel strength: PS (maximum force required to penetrate the peel in Newton), stiffness: S (slope of the force/displacement analysis, FDA, curve till peel strength in $\mathrm{N} \mathrm{mm}^{-1}$ ) and flesh firmness: FF (mean force required to penetrate flesh in Newton) were extracted from FDA curve as proposed by Nambi et al. (2015) and Camps et al. (2005). Colour coordinates were recorded for both external peel colour $\left(\mathrm{L}_{\mathrm{e}}{ }^{*}, \mathrm{a}_{\mathrm{e}}{ }_{\mathrm{e}}, \mathrm{b}_{\mathrm{e}}{ }^{*}\right)$ and internal pulp colour $\left(\mathrm{L}_{\mathrm{i}}^{*}, \mathrm{a}_{\mathrm{i}}^{*}, \mathrm{~b}_{\mathrm{i}}^{*}\right)$ of the mango using a HunterLAB colour meter (Hunter Associates Laboratory, Inc. USA) as proposed by Nambi et al. (2016b).

As ripening is a complex process, all changes related to physicochemical, colour and textural properties are highly correlated each other, so the index $\left(I_{R}\right)$ could be described as a function of all variables that change during ripening as given in Eq. (1).

$I_{R}=f$ (physicochemical, colour and textural properties). (1)

The ripeness index $\left(I_{R}\right)$ was presumed to be within the range of $0-1$ for easy adaptation and interpretation. With the measured quality parameters, hierarchical cluster analysis was used to group the whole data into 5 stages of ripening (Nambi et al., 2015) using JMP (SAS Institute Inc., USA). Among the linkage methods in hierarchical cluster analysis, Ward minimum variance method was employed to maximise the likelihood of variables in each cluster level. Each classified ripening stage was assigned a value as ripeness index $\left(I_{R}\right)$ with 0.2 interval between each stage. MLR, PLS and PCR multivariate analyses with full cross validation were employed to compare predictability of the ripeness index based on goodness of fit parameters. 
The function given in Eq. (1) is more complex, since all the quality parameters need to be estimated for the prediction of ripening level. The ultimate objective of this study was to develop $I_{R}$ with limited variables using simple models without compromising the predictability. Hence the variable reduction procedure was performed based on weightage of each quality parameter in the prediction models. High weightage quality parameters were pooled together and a separate MLR was employed for each group and the predictability of ripening stage were analysed.

The developed ripeness index $\left(I_{R}\right)$ and corresponding regression models were cross validated with the next season fruits (March - June 2015). For each variety, 3 separate sample lots were collected at 7 days intervals from the same location as mentioned above and kept for ripening in order to get different ripening stages. After 18 days of storage (days calculated from the first lot), different lot samples were mixed together and 80 fruits were selected randomly for quality analysis. Besides, 20 fruits were selected randomly from the commercial market at different ripening stages. Commercial market samples were included in the cross validation process in order to validate the model for its prediction efficacy at commercial level. So in total 100 fruits from each variety were selected and all 12 quality parameters were measured.

From the measured quality parameters, $I_{R}$ values were calculated using identified models and corresponding stage was obtained as predicted ripening stage. The actual ripening stage of each sample was obtained using the properties chart proposed by Nambi et al. (2015).
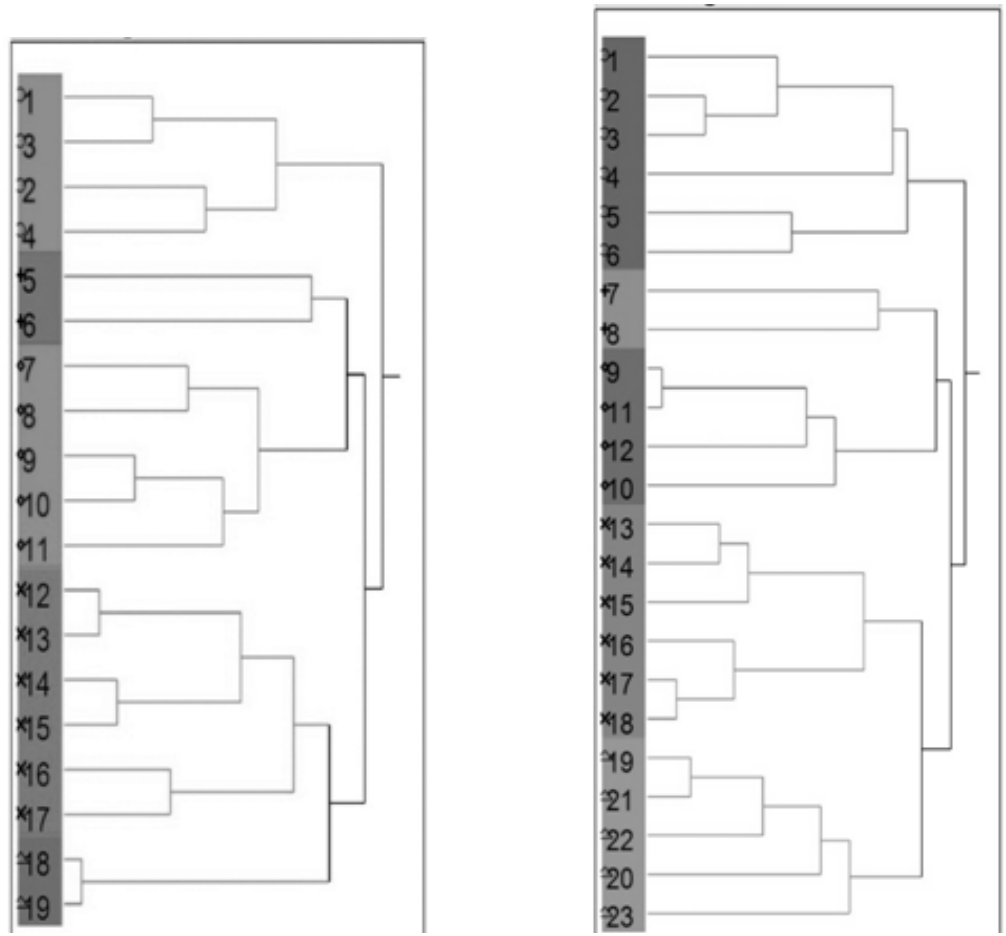

\section{RESULTS AND DISCUSSION}

From cluster analysis, the ripening period of each variety was classified into five stages based on the changes occurred in quality parameters using cluster analysis, and the stages were named as unripe (UR), early ripe (ER), partially ripe (PR), ripe (R) and over ripe/decay (OR) as proposed by Nambi et al. (2015). The dendrogram obtained from cluster analysis for each variety is given in Fig. 1.

Three multivariate regression analyses (PLS, PCR and MLR) were used for prediction and compared for their effectiveness in prediction with $\mathrm{R}^{2}$, RMSE, standard error and bias of calibration and validation. Obtained results from multivariable regression are given in Table 1. All three regression analyses predicted the ripening stage with higher $\mathrm{R}^{2}$ value, lower RMSE, standard error and bias in both calibration and validation (Table 1). Comparatively, MLR showed the best results among the three analyses for all the cultivars, with lowest RMSE, SE and bias values. Similar results were reported by Jha et al. (2007) in mango for harvest maturity prediction using colour values. This may be due to the lower number of variables. PLS and PCR would be suitable for a higher number of variables than the observation. Hence, MLR was selected for further studies. Moreover, multi linear regression would be easy for further prediction than other models. The regression coefficients are given in Table 2.

For making a more simple and effective model from the 12 variable MLR model, the variable reduction process was carried out based on the weightage of each quality

Fig. 1. Dendrograms obtained in Hierarchical cluster with five ripeness levels in Alphonso, Banganapalli and Neelam mangoes (number in the dendrogram indicates the total post-harvest life of respective fruit variety in days). 
T a b l e 1. Comparison of various multivariable regression for ripening prediction

\begin{tabular}{|c|c|c|c|c|c|c|c|c|c|}
\hline \multirow{2}{*}{$\begin{array}{l}\text { Mango } \\
\text { variety }\end{array}$} & \multirow{2}{*}{$\begin{array}{c}\text { Regres- } \\
\text { sion } \\
\text { type }\end{array}$} & \multicolumn{2}{|c|}{$\mathrm{R}^{2}$} & \multicolumn{2}{|c|}{ RMSE } & \multicolumn{2}{|c|}{ SE } & \multicolumn{2}{|c|}{ Bias } \\
\hline & & calibration & validation & calibration & validation & calibration & validation & calibration & validation \\
\hline \multirow{3}{*}{ Alphonso } & PLS & 0.985 & 0.914 & 0.029 & 0.050 & 0.030 & 0.051 & 0.000 & 0.004 \\
\hline & PCR & 0.961 & 0.948 & 0.051 & 0.628 & 0.052 & 0.064 & 0.000 & -0.003 \\
\hline & MLR & 0.990 & 0.967 & 0.026 & 0.076 & 0.027 & 0.078 & 0.000 & -0.003 \\
\hline \multirow{3}{*}{ Banganapalli } & PLS & 0.972 & 0.958 & 0.050 & 0.065 & 0.051 & 0.066 & 0.000 & -0.001 \\
\hline & PCR & 0.966 & 0.909 & 0.055 & 0.063 & 0.056 & 0.064 & 0.000 & 0.001 \\
\hline & MLR & 0.989 & 0.960 & 0.031 & 0.061 & 0.031 & 0.092 & 0.000 & -0.001 \\
\hline \multirow{3}{*}{ Neelam } & PLS & 0.976 & 0.971 & 0.040 & 0.046 & 0.041 & 0.047 & 0.000 & 0.001 \\
\hline & PCR & 0.974 & 0.899 & 0.042 & 0.048 & 0.043 & 0.050 & 0.000 & 0.001 \\
\hline & MLR & 0.991 & 0.969 & 0.025 & 0.043 & 0.026 & 0.085 & 0.000 & 0.001 \\
\hline
\end{tabular}

PLS - partial least square regression, PCR - principle component regression, MLR - multi linear regression, $\mathrm{R}^{2}$ - coefficient of determination, RMSE - root mean square error, $\mathrm{SE}$ - standard error.

T a b l e 2. Regression coefficients of selected models for ripening prediction

\begin{tabular}{|c|c|c|c|c|c|c|c|c|c|c|c|c|c|}
\hline Variable & Inter & $\mathrm{L}^{*}{ }_{\mathrm{e}}$ & $a^{*}{ }_{e}$ & $b^{*}{ }_{e}$ & $\mathrm{~L}^{*}{ }_{\mathrm{i}}$ & $\mathrm{a}^{*}{ }_{\mathrm{i}}$ & $\mathrm{b}^{*}{ }_{\mathrm{i}}$ & $\mathrm{pH}$ & TSS & TA & PS & $\mathrm{S}$ & FF \\
\hline \multicolumn{14}{|c|}{ Alphonso } \\
\hline All & 0.631 & -0.001 & 0.004 & 0.007 & -0.010 & -0.001 & -0.001 & 0.068 & 0.005 & -9.041 & 0.007 & -0.001 & -0.013 \\
\hline $\begin{array}{l}\text { External } \\
\text { colour }\end{array}$ & 0.656 & -0.016 & 0.013 & 0.013 & & & & & & & & & \\
\hline $\begin{array}{l}\text { Textural } \\
\text { properties }\end{array}$ & 0.855 & & & & & & & & & & -0.021 & -0.005 & 0.026 \\
\hline $\begin{array}{l}\text { TSS and } \\
\text { acidity }\end{array}$ & 0.139 & & & & & & & & 0.038 & -19.615 & & & \\
\hline \multicolumn{14}{|c|}{ Banganapalli } \\
\hline All & 1.288 & 0.011 & -0.001 & 0.006 & -0.019 & -0.010 & -0.002 & 0.090 & 0.005 & -33.037 & 0.001 & -0.016 & 0.001 \\
\hline $\begin{array}{l}\text { External } \\
\text { colour }\end{array}$ & -1.451 & 0.023 & 0.005 & 0.012 & & & & & & & & & \\
\hline $\begin{array}{l}\text { Textural } \\
\text { properties }\end{array}$ & 0.962 & & & & & & & & & & -0.008 & -0.017 & 0.003 \\
\hline $\begin{array}{l}\text { TSS and } \\
\text { acidity }\end{array}$ & 0.656 & & & & & & & & 0.036 & -90.836 & & & \\
\hline \multicolumn{14}{|c|}{ Neelam } \\
\hline All & 1.987 & -0.006 & -0.001 & -0.001 & -0.018 & -0.002 & 0.001 & 0.120 & -0.002 & -9.888 & 0.000 & -0.003 & -0.004 \\
\hline $\begin{array}{l}\text { External } \\
\text { colour }\end{array}$ & -0.449 & 0.015 & 0.010 & 0.001 & & & & & & & & & \\
\hline $\begin{array}{l}\text { Textural } \\
\text { properties }\end{array}$ & 0.776 & & & & & & & & & & -0.007 & -0.013 & -0.001 \\
\hline $\begin{array}{l}\text { TSS and } \\
\text { acidity }\end{array}$ & -0.157 & & & & & & & & 0.044 & -15.816 & & & \\
\hline
\end{tabular}

Inter - intercept, TSS - total soluble solids, TA - titrable acidity, PS - peel strength, S - stiffness, FF - flesh firmness. 
T a b l e 3. Weightage ( $t$-values) of each quality parameter in MLR model in ripening prediction

\begin{tabular}{|c|c|c|c|c|c|c|c|c|c|c|c|c|c|}
\hline $\begin{array}{c}\text { No.varia- } \\
\text { bles }\end{array}$ & $\begin{array}{l}\text { Para- } \\
\text { meters }\end{array}$ & $\mathrm{L}_{\mathrm{e}}^{*}$ & $a^{*}{ }_{e}$ & $\mathrm{~b}^{*}{ }_{\mathrm{e}}$ & $\mathrm{L}^{*}{ }_{\mathrm{i}}$ & $a^{*}$ & $\mathrm{~b}^{*}{ }_{\mathrm{i}}$ & $\mathrm{pH}$ & TSS & TA & PS & $\mathrm{S}$ & $\mathrm{FF}$ \\
\hline \multicolumn{14}{|c|}{ Alphonso } \\
\hline 12 & All & -0.12 & 0.99 & 1.46 & -1.93 & -0.26 & -0.30 & 1.97 & 0.42 & -2.07 & 1.79 & -0.08 & -2.16 \\
\hline 6 & $\begin{array}{l}\text { Colour } \\
\text { properties }\end{array}$ & 5.59 & -0.76 & 2.18 & 3.17 & -3.75 & 0.05 & -0.50 & & & & & \\
\hline 3 & External colour & -2.72 & 4.74 & 3.19 & & & & & & & & & \\
\hline 3 & Internal colour & & & & -5.59 & 4.47 & -3.45 & & & & & & \\
\hline 3 & $\begin{array}{l}\text { Textural } \\
\text { properties }\end{array}$ & & & & & & & & & & -4.34 & -0.39 & 2.32 \\
\hline 3 & $\begin{array}{l}\mathrm{pH}, \mathrm{TSS} \text { and } \\
\text { acidity }\end{array}$ & & & & & & & 3.88 & 4.50 & -5.14 & & & \\
\hline 2 & TSS and acidity & & & & & & & & 10.16 & -6.95 & & & \\
\hline \multicolumn{14}{|c|}{ Banganapalli } \\
\hline 12 & All & 3.47 & -0.50 & 3.35 & -3.83 & -3.74 & -2.63 & 3.61 & 1.78 & -4.43 & 0.42 & -4.42 & 0.13 \\
\hline 6 & $\begin{array}{l}\text { Colour } \\
\text { properties }\end{array}$ & 5.80 & 0.00 & 3.23 & -4.79 & -2.75 & 0.36 & & & & & & \\
\hline 3 & External colour & 4.07 & 4.55 & 4.27 & & & & & & & & & \\
\hline 3 & Internal colour & & & & -3.12 & -2.11 & 1.31 & & & & & & \\
\hline 3 & $\begin{array}{l}\text { Textural } \\
\text { properties }\end{array}$ & & & & & & & & & & -5.60 & -1.06 & 0.20 \\
\hline 3 & $\begin{array}{l}\mathrm{pH}, \mathrm{TSS} \text { and } \\
\text { acidity }\end{array}$ & & & & & & & 1.87 & 3.28 & -3.39 & & & \\
\hline 2 & TSS and acidity & & & & & & & & 5.37 & -10.08 & & & \\
\hline \multicolumn{14}{|c|}{ Neelam } \\
\hline 12 & All & -1.40 & -0.40 & -0.34 & -5.66 & -0.34 & 0.33 & 2.94 & -0.36 & -2.33 & -0.16 & -0.29 & -1.56 \\
\hline 6 & $\begin{array}{l}\text { Colour } \\
\text { properties }\end{array}$ & -0.09 & 3.93 & -1.11 & -5.11 & 1.79 & 0.12 & & & & & & \\
\hline 3 & External colour & 2.34 & 3.00 & 0.35 & & & & & & & & & \\
\hline 3 & Internal colour & & & & -5.12 & 1.66 & 1.20 & & & & & & \\
\hline 3 & $\begin{array}{l}\text { Textural } \\
\text { properties }\end{array}$ & & & & & & & & & & -1.64 & -0.75 & -0.15 \\
\hline 3 & $\begin{array}{l}\mathrm{pH}, \mathrm{TSS} \text { and } \\
\text { acidity }\end{array}$ & & & & & & & 2.07 & 1.66 & -2.43 & & & \\
\hline 2 & TSS and acidity & & & & & & & & 6.07 & -3.85 & & & \\
\hline 2 & TSS and acidity & & & & & & & & 2.66 & 9.62 & & & \\
\hline
\end{tabular}

Explanations as in Table 2.

parameter on the prediction. Properties like colour coordinates (6 parameters), textural characteristic (3 parameters) and physicochemical properties (TSS, $\mathrm{pH}$ and acidity) were grouped as individual groups and evaluated in prediction. The weightage of each quality parameter was found based on t-values is given in Table 3. The goodness of fit parameters for the 12 variable MLR model are given in Table 4 , and higher $\mathrm{R}^{2}(>0.94)$ was found with the 12 variables model.

While using MLR with all the colour coordinates (6 parameters) together for prediction, external $L^{*}$ value was found to be a highly influencing parameter, followed by internal $\mathrm{L}^{*}$ then by other coordinates in Alphonso and 
T a b l e 4. Goodness of fit parameters at different level of variable while using MLR for ripening prediction

\begin{tabular}{|c|c|c|c|c|c|c|c|c|c|c|c|}
\hline \multirow{2}{*}{ Model } & \multirow{2}{*}{$\begin{array}{c}\text { No. } \\
\text { variables }\end{array}$} & \multirow{2}{*}{$\begin{array}{l}\text { Quality } \\
\text { parameters }\end{array}$} & \multicolumn{3}{|c|}{ Alphonso } & \multicolumn{3}{|c|}{ Banganapalli } & \multicolumn{3}{|c|}{ Neelam } \\
\hline & & & $\mathrm{R}^{2}$ & RMSE & $\chi^{2}$ & $\mathrm{R}^{2}$ & RMSE & $\chi^{2}$ & $\mathrm{R}^{2}$ & RMSE & $\chi^{2}$ \\
\hline \multirow{8}{*}{ MLR } & 12 & All & 0.962 & 0.061 & 0.004 & 0.992 & 0.030 & 0.001 & 0.936 & 0.064 & 0.004 \\
\hline & 6 & $\begin{array}{l}\text { Colour } \\
\text { properties }\end{array}$ & 0.947 & 0.068 & 0.005 & 0.969 & 0.056 & 0.003 & 0.919 & 0.077 & 0.006 \\
\hline & 3 & $\begin{array}{l}\text { External } \\
\text { colour }\end{array}$ & 0.919 & 0.082 & 0.007 & 0.951 & 0.068 & 0.005 & 0.808 & 0.128 & 0.016 \\
\hline & 3 & $\begin{array}{l}\text { Internal } \\
\text { colour }\end{array}$ & 0.928 & 0.077 & 0.006 & 0.883 & 0.105 & 0.011 & 0.812 & 0.102 & 0.010 \\
\hline & 3 & $\begin{array}{l}\text { Textural } \\
\text { properties }\end{array}$ & 0.860 & 0.114 & 0.013 & 0.929 & 0.082 & 0.007 & 0.801 & 0.129 & 0.017 \\
\hline & 3 & $\begin{array}{l}\mathrm{pH}, \mathrm{TSS} \\
\text { and acidity }\end{array}$ & 0.937 & 0.072 & 0.005 & 0.896 & 0.112 & 0.013 & 0.828 & 0.101 & 0.010 \\
\hline & 2 & $\begin{array}{l}\text { TSS and } \\
\text { Acidity }\end{array}$ & 0.929 & 0.081 & 0.006 & 0.889 & 0.114 & 0.013 & 0.813 & 0.123 & 0.015 \\
\hline & 2 & $\begin{array}{l}\text { External } \\
\mathrm{L}^{*} \text { and } \mathrm{a}^{*}\end{array}$ & 0.910 & 0.08 & 0.006 & 0.927 & 0.080 & 0.007 & 0.807 & 0.122 & 0.015 \\
\hline $\begin{array}{l}2 \text { nd } \\
\text { order }\end{array}$ & 2 & $\begin{array}{l}\text { External } \\
a^{*} \text { and } b^{*}\end{array}$ & 0.916 & 0.083 & 0.007 & 0.934 & 0.078 & 0.006 & 0.796 & 0.126 & 0.016 \\
\hline Linear & 1 & \multirow{2}{*}{ TSS } & 0.846 & 0.110 & 0.012 & 0.642 & 0.181 & 0.033 & 0.658 & 0.136 & 0.019 \\
\hline Quad & 1 & & 0.860 & 0.106 & 0.085 & 0.651 & 0.179 & 0.027 & 0.670 & 0.119 & 0.010 \\
\hline Linear & 1 & \multirow{2}{*}{ Acidity } & 0.764 & 0.136 & 0.019 & 0.797 & 0.136 & 0.018 & 0.561 & 0.154 & 0.024 \\
\hline Quad & 1 & & 0.770 & 0.130 & 0.017 & 0.801 & 0.117 & 0.010 & 0.560 & 0.174 & 0.001 \\
\hline Linear & 1 & \multirow{2}{*}{ External a } & 0.704 & 0.176 & 0.020 & 0.770 & 0.160 & 0.016 & 0.541 & 0.184 & 0.029 \\
\hline Quad & 1 & & 0.710 & 0.180 & 0.017 & 0.780 & 0.161 & 0.010 & 0.540 & 0.184 & 0.028 \\
\hline Linear & 1 & \multirow{2}{*}{ PS } & 0.808 & 0.122 & 0.015 & 0.915 & 0.088 & 0.008 & 0.698 & 0.128 & 0.016 \\
\hline Quad & 1 & & 0.810 & 0.100 & 0.110 & 0.919 & 0.087 & 0.004 & 0.710 & 0.087 & 0.011 \\
\hline
\end{tabular}

MLR - multi linear regression, Quad - quadratic model, $\mathrm{R}^{2}$ - coefficient of determination, RMSE - root mean square error, $\chi^{2}-$ Chisquare value.

Banganapalli (Table 3). This may be due to a change in external peel colour from dull green to bright yellowish red, and a change in internal colour from bright white to dark yellow during ripening. But a different scenario was observed in Neelam, for which the internal $L^{*}$ value was found as highly influencing a parameter, followed by the external $\mathrm{a}^{*}$ value. This might be due to non-uniform colour change that occurred on the peel of Neelam mangoes. From the Table 4, it could be observed that prediction of ripening stage using the 6 colour variables model was more effective, with higher $\mathrm{R}^{2}(>0.91)$ and lower RMSE and chi-squared values in all of the mango cultivars. The regression coefficients of the six-variable model are given in Table 2.

Further to reduce the variables, MLR with 3 variables was evaluated using internal and external colour coordinates as separate groups. Unlike the 6 parameter model, the external a* value had higher influence on prediction than $\mathrm{L}^{*}$ and $b^{*}$ in all cultivars of mango while using external colour for prediction. On the other hand, while using internal colour for prediction, $\mathrm{L}^{*}$ exhibited a higher influence, followed by $a^{*}$ and $b^{*}$ in all the three mango cultivars. 
Multi linear regression models from both internal and external colour groups exhibited similar goodness of fit results in prediction in all mango cultivars (Table 4). From these findings, the 3 -variable MLR model with the external colour coordinates would be suitable rather than with the internal colour coordinates, since external colour coordinates can be measured in non-destructive way. The regression coefficients of the 3-variable model (external colour coordinates) are given in Table 2.

Among the three textural characteristics, peel strength was found to be the most influential variable in all the mango cultivars. Flesh firmness was found to be the second influential variable in Alphonso mangoes, which may be due to physiological variations between cultivars which lead to fast softening of fruit pulp in Alphonso compared to Banganapalli and Neelam mangoes. From Table 4, it could be noticed that MLR model based on textural characteristics would be more suitable to predict the ripening stages in Banganapllai, with higher $\mathrm{R}^{2}$ values $(>0.90)$ and lower RMSE and chi-squared values than the other two mango cultivars. The regression coefficients of the MLR model based on three textural characteristics are given in Table 2 .

Among the three physicochemical properties (TSS, pH and acidity), acidity was found to be a highly influential variable, followed by TSS in Alphonso and Neelam. But in Banganapalli mangoes both TSS and acidity exhibited on par influence in the prediction model. Using MLR with three variables (physicochemical properties), effective prediction of ripening stages was achieved in Alphonso and Banganapalli, with higher $\mathrm{R}^{2}$ value $(>0.90)$, lower RMSE and chi-squared values. In the case of Neelam, prediction was not on par with the other two cultivars $\left(\mathrm{R}^{2}<0.90\right)$. This may be due to physiological variations between the cultivars. The regression coefficients of the MLR model with TSS, $\mathrm{pH}$ and acidity are given in Table 2 .

For further reduction in variables, two highly influential variables from MLR models containing external colour coordinates ( $\mathrm{L}$ and a) and physicochemical properties (TSS and acidity) were selected and evaluated in prediction. The model with TSS and acidity exhibited on par result with the three variable MLR model which contain TSS, acidity and $\mathrm{pH}$. Hence, the two variable MLR model with TSS and acidity would be suitable for prediction of ripening stages in all mango cultivars rather than the three variable MLR model.

The MLR model with external $\mathrm{L}^{*}$ and $\mathrm{a}^{*}$ showed better results in prediction. A second order polynomial model with the external $\mathrm{a}^{*}$ and $\mathrm{b}^{*}$ as proposed by Jha et al. (2007) was also evaluated and found to produce on par results with the model containing external $\mathrm{L}^{*}$ and $\mathrm{a}^{*}$ colour coordinates. Though, these two variable models exhibited contending results (Table 4) in the prediction, MLR model containing three external colour coordinates would be more suitable, since the model exhibited more effective results than other colour based models. Moreover, all the three colour coordinates $\left(\mathrm{L}_{\mathrm{e}}{ }^{*}, \mathrm{a}_{\mathrm{e}}{ }^{*}\right.$ and $\left.\mathrm{b}_{\mathrm{e}}{ }^{*}\right)$ can be measured simultaneously in the same device and they can be used together.

In order to make the prediction model most simple, highly influential variables from the three variable models were selected and evaluated for their predictability of ripening stage. Totally four quality parameters (TSS, acidity, external $\mathrm{a}^{*}$ and PS) were selected for single variable evaluation both in linear and quadratic form. Higher order models did not yield fruitful results with a single variable, hence the modelling was limited to 2 nd order (quadratic) form. Though acidity was a highly influential variable among TSS, pH and acidity, TSS was also selected for single variable evaluation, since TSS is an easy as well as readily measurable parameter with handheld refractometer. The model containing TSS was found comparatively better in predicting ripening stage in Alphonso mangoes than in the other cultivars. Peel strength based model was found better in ripening prediction in Banganapalli than in the other cultivars. Overall, single variable models did not perform effectively in prediction and yielded lower $\mathrm{R}^{2}$ values (Table 2). Therefore, single variable models should be avoided for prediction of ripening stages.

Ripening index and RPI were compared for their suitability and effectiveness using observed values from the cross validation set (100 fruits). All 12 quality parameters were measured and $I_{R}$ values were calculated using the 12 parameter MLR model. RPI was also calculated using the existing formulae. Comparison of RPI with the proposed $I_{R}$ is given in the form of box plot with outliers (Fig. 2). Similar trend of RPI values was observed in all three cultivars. From Fig. 2a, overlaps could be observed between various ripening stages in RPI values, especially adjacent ripening stages like UR with ER and PR with R. Around $75 \%$ of RPI values of UR and ER stages were found overlapping with each other. Likewise, on par RPI values of PR and R stages were found in Banganapalli and Neelam.

Higher variation in RPI values in the last stage (OR) was observed in Alphonso (Fig. 2a). This may be due to a decrease in TSS, especially in Alphonso, observed towards the end of ripening, where decay of fruit starts. From these results it could be concluded that RPI could only be used to predict whether the mango is raw (higher RPI values represents unripe mango) or ripe (lower RPI values represents ripe mango), rather than to predict different stages/ levels of ripening.

On the other hand, the proposed $I_{R}$ provided clear demarcation between ripening stages without any overlapping between the stages (Fig. 2b). Moreover, using $I_{R}$ a ripening stage can be easily identified emphatically, since the $I_{R}$ varies within the defined range of values (0-1).

From the variable reduction studies, best resulting and suitable models were taken for external cross validation with the next season mangoes (March-June, 2015). The 


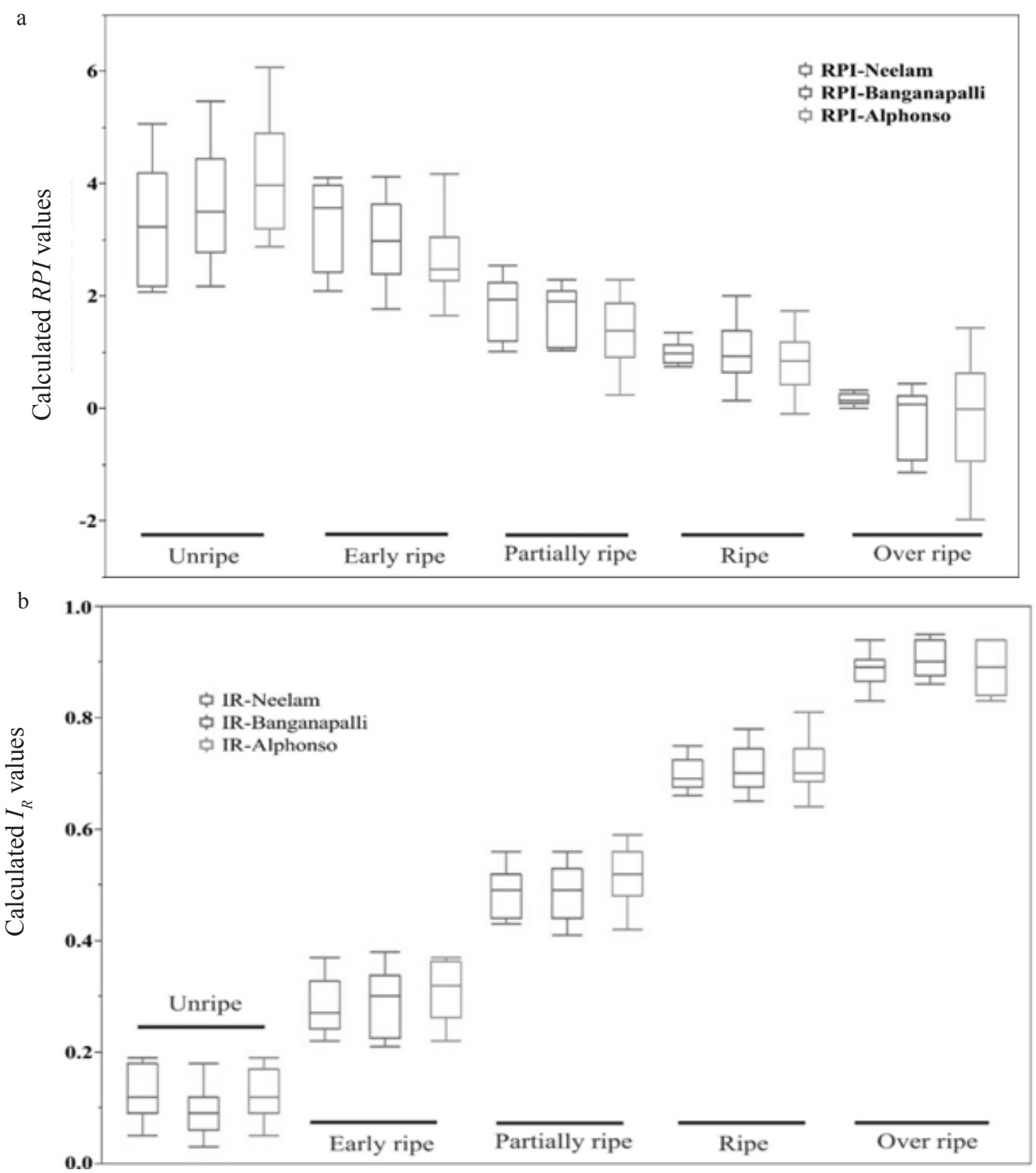

Fig. 2. Comparison of RPI and $I_{R}$ with five ripening stages for three mango varieties: a - box plot for RPI values, $\mathrm{b}-\mathrm{box}$ plot for $I_{R}$ values.

actual and predicted ripening stages/levels were compared and plotted based on the number of correct predictions in each variety (Fig. 3).

While using MLR with all 12 quality parameters, $100 \%$ correct prediction was achieved in Alphonso and Banganapalli mangoes, but in Neelam around $99 \%$ correct prediction was achieved. In external cross validation, the models with colour coordinates exhibited effective prediction. Either of the 6-variable (all internal and external colour) model or the 3-variable (external colour) model exhibited similar results in cross validation and effectively predicted the ripening stages of all mango cultivars with more than $98 \%$ correct prediction (Fig. 3). Hence it could be concluded that instead of the 6-variable complex MLR, the 3-variable model (Eq. (2)) containing external colour coordinates would be sufficient for predicting ripening stage. Another three variables model with textural characteristics was also tested in the cross validation and the results are shown in Fig. 3. Though the MLR model with 3 textural characteristics resulted in good prediction, the MLR model with 3 external colour coordinates would be more suitable, since colour coordinates are easy to measure with hand held colorimeter and comparatively cost effective compared to texture analysis, moreover the model with external colour exhibited better results than the model with textural parameters.

$$
I_{R}=\operatorname{Intercept}+x L_{e}^{*}+y a_{e}^{*}+z b_{e}^{*},
$$




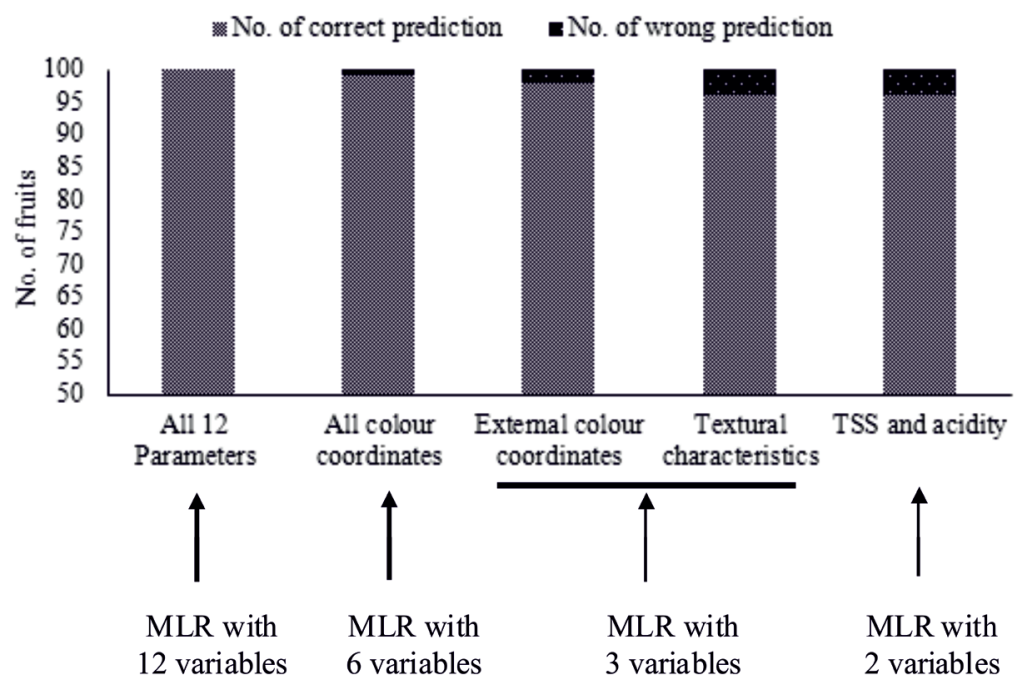

b

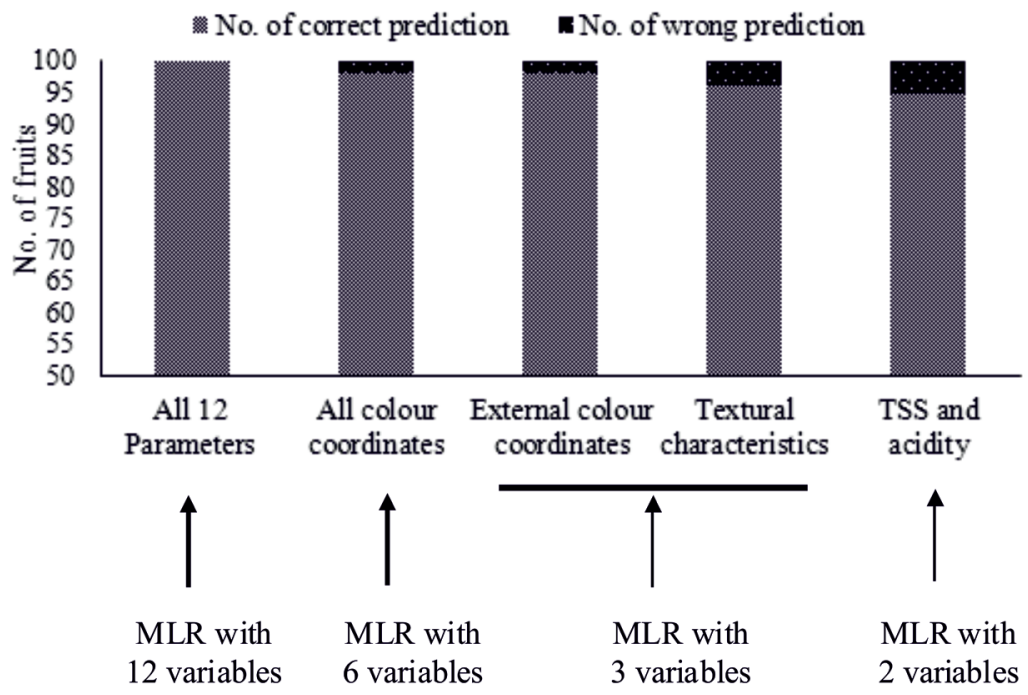

c

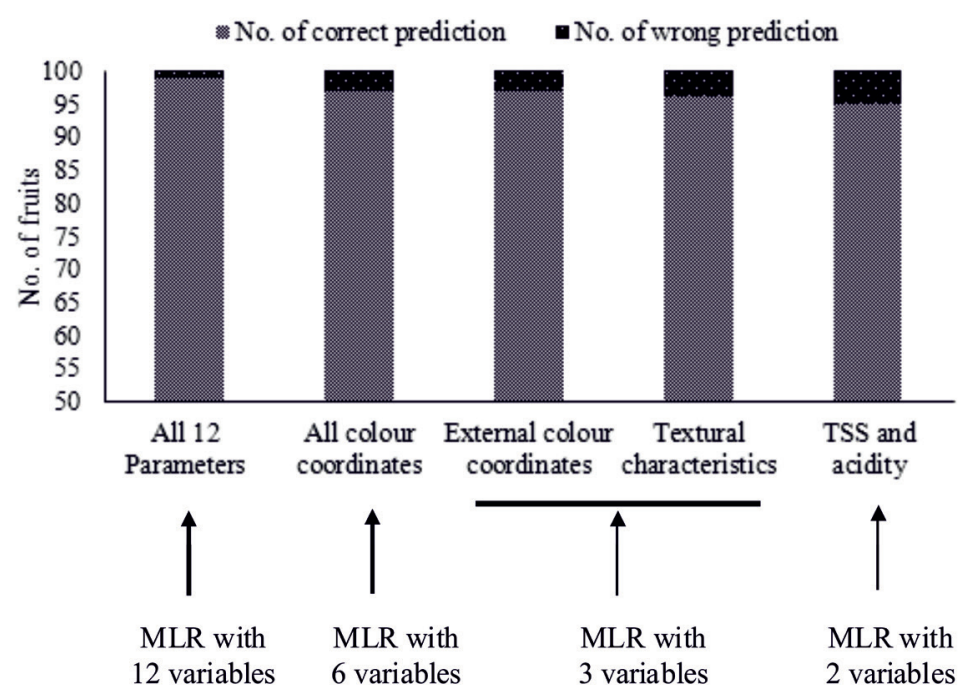

Fig. 3. Results of cross validation with No. of fruit correctly predicted in: a - Alphonso, b-Banganapalli, and c - Neelam mangoes. 


$$
I_{R}=\text { Intercept }+x T S S+y T A,
$$

where: $x, y$ and $z$ are corresponding coefficients for the corresponding quality parameters (Table 2 ).

More than $95 \%$ correct prediction was achieved with the two variables model using TSS and acidity. Hence the model (Eq. (3)) with TSS and acid content could be very useful for quick and easy prediction which needs minimum inputs and at the same time produces comparable results to those that can be achieved with the 12 variable MLR model.

\section{CONCLUSIONS}

1. The developed index and its multilinear regression models were found effective in the prediction of ripeness level or stage in all the three cultivars of mango.

2. The developed models were further simplified using variable reduction techniques, for rapid and easy prediction.

3. Better prediction was achieved using multi linear models with 2 variables (total soluble solids and acidity) and 3 variables of colour (external L*, $\mathrm{a}^{*}$ and $\mathrm{b}^{*}$ ) coordinates.

4. These simple models would be suitable for processors and other commercial applications where reasonable accuracy is required. However, the accuracy could be improved with 12 quality parameters wherever required.

Conflict of interest: The Authors do not declare conflict of interest.

\section{REFERENCES}

Bashir H.A. and Abu-Goukh A.-B.A., 2003. Compositional changes during guava fruit ripening. Food Chemistry, 80, 557-563.

Blanes C., Cortés V., Ortiz C., Mellado M., and Talens P., 2015. Non-destructive assessment of mango firmness and ripeness using a robotic gripper. Food and Bioprocess Technology 8, 1914-1924.

Brady C., 1987. Fruit ripening. Annual Review of Plant Physiol., 38, $155-178$.

Camps C., Guillermin P., Mauget J., and Bertrand D., 2005. Data analysis of penetrometric force/displacement curves for the characterization of whole apple fruits. J. Texture Studies, 36, 387-401.

Charles R. and Tung M., 1973. Physical, rheological and chemical properties of bananas during ripening. J. Food Sci., 38, 456-459.

Chen C. and Ramaswamy H., 2002. Color and texture change kinetics in ripening bananas. LWT-Food Sci. Technol., 35, 415-419.
Jha S., Chopra S., and Kingsly A., 2007. Modeling of color values for nondestructive evaluation of maturity of mango. J. Food Eng., 78, 22-26.

Joas J., Caro Y., and Lechaudel M., 2009. Comparison of postharvest changes in mango ( $c v$. Cogshall) using a Ripening class index (Rci) for different carbon supplies and harvest dates. Postharvest Biol. Technol., 54, 25-31.

Kienzle S., Sruamsiri P., Carle R., Sirisakulwat S., Spreer W., and Neidhart S., 2012. Harvest maturity detection for 'Nam Dokmai\# 4'mango fruit (Mangifera indica L.) in consideration of long supply chains. Postharvest Biol. Technol., 72, 64-75.

Lizada C., 1993. Mango. In: Biochemistry of fruit ripening (Eds G.B. Seymour, J.E. Taylor, G.A. Tucker), Springer Press, Netherlands.

Nambi V.E., Thangavel K., and Jesudas D.M., 2015. Scientific classification of ripening period and development of colourgrade chart for Indian mangoes (Mangifera indica L.) usingmultivariate cluster analysis. Scientia Horticulturae, 193, 90-98.

Nambi V.E., Thangavel K., Rajeswari K.A., Manickavasagan A., and Geetha V., 2016a. Texture and rheological changes of Indian mango cultivars during ripening. Postharvest Biol. Technol., 117, 152-160.

Nambi V.E., Thangavel K., Shahir S., and Chandrasekar V., 2016b. Colour kinetic during ripening of Indian mangoes. Int. J. Food Properties, 19, 2147-2155.

Padda M.S., do Amarante C.V., Garcia R.M., Slaughter D.C., and Mitcham E.J., 2011. Methods to analyze physicochemical changes during mango ripening: A multivariate approach. Postharvest Biol. Technol., 62, 267-274.

Prasanna V., Prabha T.N., and Tharanathan R.N., 2007. Fruit ripening phenomena - an overview. Critical Reviews in Food Science and Nutrition, 47, 1-19.

Rungpichayapichet P., Mahayothee B., Nagle M., Khuwijitjaru P., and Müller J., 2016. Robust NIRS models for nondestructive prediction of postharvest fruit ripeness and quality in mango. Postharvest Biol. Technol., 111, 31-40.

Saranwong S., Sornsrivichai J., and Kawano S., 2004. Prediction of ripe-stage eating quality of mango fruit from its harvest quality measured nondestructively by near infrared spectroscopy. Postharvest Biol. Technol., 31, 137-145.

Saxena M. and Gandhi C.P., 2015. Indian Horticulture database 2014. National Horticulture Board, Ministry of Agriculture, Government of India, New Delhi, India.

Seymour G.B., Taylor J.E., and Tucker G.A., 1993. Biochemistry of fruit ripening. Chapman and Hall, Malaysia.

Stover R.H. and Simmonds N.W., 1987. Bananas. Longman Scientific and Technical, Essex, England.

Vásquez-Caicedo A.L., Sruamsiri P., Carle R., and Neidhart S., 2005. Accumulation of all-trans- $\beta$-carotene and its 9 -cis and 13-cis stereoisomers during postharvest ripening of nine Thai mango cultivars. J. Agricultural Food Chemistry, $53,4827-4835$. 